\title{
Growing mathematical learners
}

\author{
Naomi Ingram \\ University of Otago
}

Results in the International Trends in Mathematics and Sciences Study, and the National Monitoring Study of Student Achievement, have meant there has been recent focus on mathematics education in New Zealand. As with previous iterations of assessment result reports, the quality of teachers, teaching, teacher education, professional learning, mathematics programmes and curriculum have been questioned by the media. It seems that change in mathematics education in New Zealand may, once again, be imminent. In this paper, there is a plea that any change needs to retain what is positive about mathematics education in New Zealand. Teachers need to be supported to grow their own mathematics content knowledge and pedagogical content knowledge so they can make autonomous and sound decisions for their own students' needs, while retaining the ethic of care they already foster in their classrooms. Support needs to be in the form of rich, centrally managed yet locally adapted, non-divisive resources and professional learning.

Furthermore, any change to mathematics education in New Zealand needs to be centred around students and teachers engaging in authentic mathematics practice. A challenging task approach is described that supports this practice, which has been successfully trialled with New Zealand teachers. In this approach, content is not pre-taught. Rather, teachers support the students to solve challenging tasks by moving through the phases of Launch, Explore, Summarise, and Reflect.

Keywords: mathematics, challenge, TIMSS, teacher education, NMSSA

\section{Introduction}

The recent results of New Zealand students in national and international assessments have resulted in a national focus on mathematics education by policy makers, curriculum writers, educational leaders and the media. This focus demonstrates that having the ability and inclination to use mathematics effectively remains important for individuals in our technologically-rich, data-driven society. In this paper, the recent results are discussed, and suggestions are put forward for growing teachers' relationships with the learning area. Furthermore, a structure is suggested for presenting students with worthwhile and challenging mathematics, including the reasoning and methods valued by mathematicians.

\section{Measuring New Zealand students' mathematics achievement}

New Zealand students' achievement results in the 2019 international Trends in Mathematics and Sciences Study (TIMSS) (Mullis et al., 2020) made for sobering reading. Just over four in 10 of the sampled New Zealand students met the standards expected in 
mathematics, placing New Zealand students' results below many other OECD countries. These statistics are concerning, but do need to be taken in context. New Zealand has real and important differences in educational systems and society compared to countries who performed well, and New Zealand students were not necessarily exposed to, or drilled in, the content they encountered in the assessment.

At a national level however, the results of New Zealand students in mathematics are also concerning. Wānangatia te Putanga Tauira, the National Monitoring Study of Student Achievement (NMSSA), assesses New Zealand students' achievement at Year 4 (aged around 8 years old) and Year 8 (aged around 12 years old). In the most recent mathematics assessment (NMSSA, 2019), at Year 4, 81\% of students were assessed as achieving at or above expectations (Level 2 of the New Zealand Curriculum), but in Year 8, only $45 \%$ of students achieved at or above curriculum expectations (Level 4 of the New Zealand Curriculum). These statistics need to be considered in relation to the curriculum levels. As can be seen in Figure 1, in Year 4, the students generally work within Level 2. It might be expected therefore that a large proportion of students would be achieving at that level. It is, however, common practice that Curriculum Level 4 remains the main focus when the students are in Year 9. Given students have likely only engaged in some of Curriculum Level 4 by the end of Year 8 , this may explain some of the differences between the Year 4 and Year 8 results.

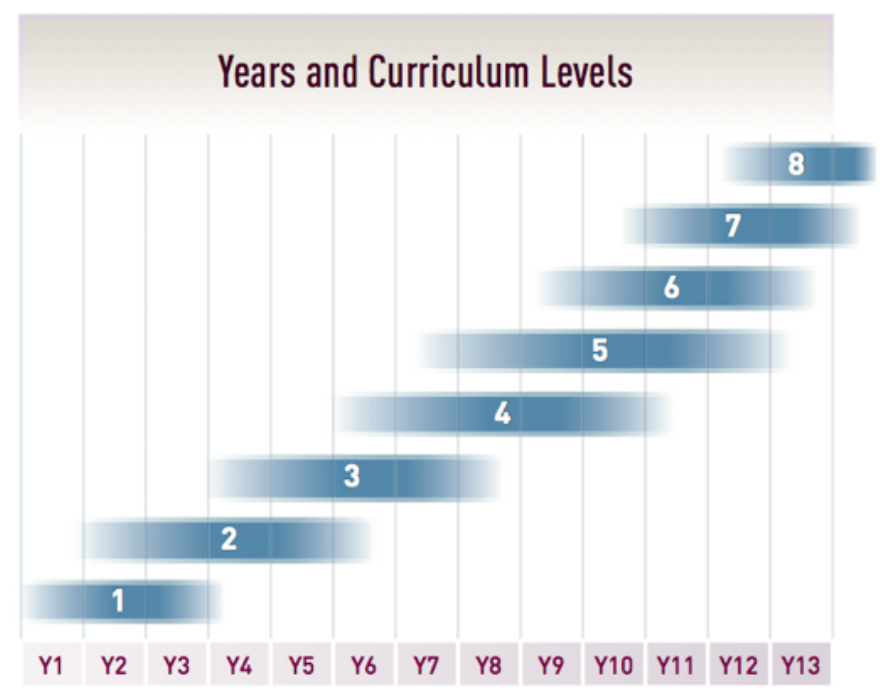

Figure 1. Curriculum levels in the New Zealand Curriculum (Ministry of Education, 2007, p. 45)

Recent media coverage has held mathematics education in New Zealand to account because of these mathematics results (e.g., Radio New Zealand, 9 December 2020). Policy, curriculum, leadership, professional development programmes, teacher education institutions, and teachers of mathematics have been discussed in relation to these results (e.g., Simon Collins, New Zealand Herald, 2 February 2021). For example, there has been some commentary regarding whether teachers at the primary school level lack mathematical content knowledge, and commentary regarding aspects of primary teachers' practice, such as their emphasis on Number compared with Geometry and Statistics. 
The media did not emphasise a potentially positive result from the recent assessments. In the 2018 NMSSA study (NMSSA, 2019), most New Zealand students surveyed were positive or very positive about learning mathematics, most students expressed confidence as mathematics learners in general, and most students rated the difficulty of their mathematics learning as 'about right to me.'

\section{The importance of challenge}

These results about students' confidence and comfort with the subject of mathematics is both interesting and worrying. Positive mathematical affect, such as confidence, is known to relate to learning outcomes such as achievement and engagement (Hannula, 2017). However, given these same students are not meeting the expectations of achievement at a national or international level, it implies the mathematics they are experiencing in the classroom may not be challenging enough.

This profile of confident students, comfortable with the level of mathematics they are doing, is not surprising when considered in relation to Ingram, Asil, Berg and Smith's (2017) analysis of previous NMSSA data. They compared the mathematics self-efficacy (confidence) of the Year 4 and Year 8 teachers in the NMSSA survey with the pedagogies they reported using in their classrooms, aligning these with Anthony and Walshaw's (2009) effective pedagogies that focus students on mathematics learning. In Ingram et al.'s (2017) analysis, all teachers built an ethic of care in their classrooms. This effective pedagogy, based on the work of Noddings (1995), is described by Anthony and Walshaw (2009) as developing caring and trusting classroom communities, where cultures that students bring to the classrooms are respected and valued. In a classroom with a strong ethic of care, teachers get to know their students well, and students build positive mathematical identities. Having an ethic of care seems valuable, and no doubt impacts the result that New Zealand students are comfortable with mathematics.

However, Ingram and colleagues (2017), also found that, when teachers had a low level of confidence or were only moderately confident in their practice (as most of the teachers were), this made a difference to the effectiveness of other pedagogies strongly related to the learning of mathematics. For example, highly confident teachers more frequently supported students to communicate mathematically, to make connections, and highly confident teachers more frequently were able to build on students' thinking. Those teachers who were not as confident enacted pedagogies known to be effective much less frequently.

Given New Zealand teachers already establish an ethic of care in their classrooms, they need support to grow their confidence to enact other pedagogies consistent with learning mathematics such as encouraging mathematical communication, including argumentation and reasoning, making connections between learners, and providing tasks that have suitable challenge. Indeed, these pedagogies described are similar to a problemsolving approach and consistent with the authentic processes of doing mathematics experienced by mathematicians (Holton, 1993). In authentic mathematics practice, students move from 'not knowing' to 'knowing.' 'Not knowing' is an important step in the mathematics problem-solving process and can be daunting for students. Therefore, confusion, perseverance, and productive struggle need to be normalised and accepted facets of the routine of doing mathematics (Ingram, 2019). 


\section{Growing mathematical learners}

Figure 2 provides a useful structure for lessons that enable teachers to enact authentic mathematics practice.

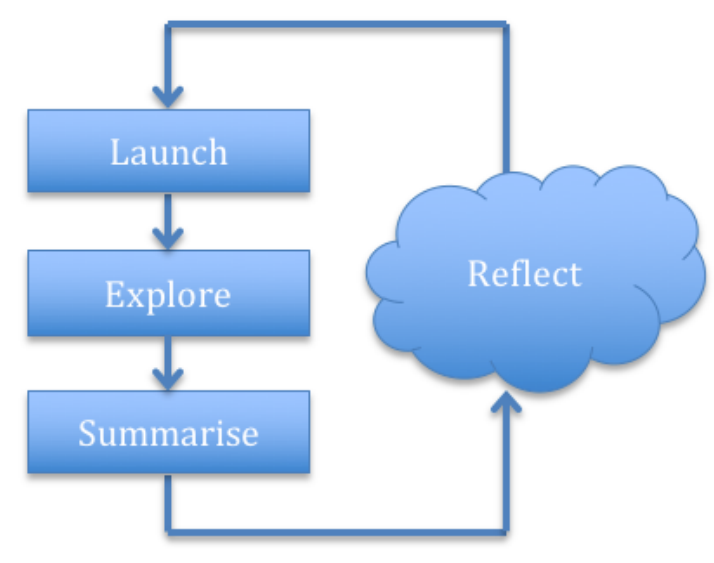

Figure 2. A cycle of challenge (Adapted from Ingram et al., 2019, p. 507)

This lesson structure is intended as an alternative to doing problems after pre-teaching the content. This structure has four cyclical phases of launch, explore, summarise and reflect, which might take place twice within one session or might evolve over several days or weeks. This suggested lesson structure is informed by the Challenging Task Project (Sullivan, 2015) with a further iteration of the project adding a reflection phase (Ingram et al., 2019).

In this approach, the teacher chooses rich, worthwhile tasks that have different contexts, that relate to students in different ways, which take different amounts of time to solve, and that highlight the utility of a range of problem-solving strategies. In other words, tasks should be challenging in the sense they are not immediately solvable. In this approach, the teachers do not pre-teach the content because, knowing their students well, they anticipate at least one student in the class has the content knowledge needed to engage in the task, or at least one student in the class knows where to seek that knowledge from.

Launch: A task is launched by supplying the students with a task both in a written and verbal form. At this stage, the teacher does not suggest which strand of mathematics might be used. Rather, they only answer questions to clarify the task, without suggesting a solution or solution pathway.

Explore: The students then enter the 'explore' phase. During this time, they might have individual thinking time before talking to other students about the problem. Here, the students will enter the zone of confusion, a state of confusion before a pathway for solving the problem has been identified. The teacher needs to hold back at this stage, without rescuing the students or telling them the answers. They can give carefully planned prompts, to scaffold or enable the students, or ask questions. Furthermore, a wide range of materials is made available at the side of the classroom that the students can chose from to model the problem. 
Summarise: Through observation and questioning, the teacher decides when to pause the 'explore phase' and which student or group of students will be asked to report back on progress. Using technology such as 'Show Me' or 'Educreations' is useful for capturing the problem-solving so it can be shared with the class (see Ingram, 2015). At this stage, class discussion is encouraged so that the students can discuss the mathematics as a group, and the teacher should encourage argumentation and reasoning. Then, the teacher summarises the progress and the learning thus far. The teacher crafts this summary to emphasise the mathematics learning intentions of the lesson. The teacher might even pause the lesson at this point for reinforcement or practice of a skill. Then, the teacher launches the task again. This cycle of launch-explore-report-summarise can continue as the students gets closer to a solution, whether it takes ten minutes or two weeks to solve a problem.

Reflect: At the beginning and/or end of each cycle or lesson, teachers ask students to reflect on their mathematical learning from the previous lesson, specifically the knowledge they utilised and the mathematical connections they made. Teachers can also ask the students to reflect on the processes of doing the mathematics. This is an opportunity for the teachers to make explicit that confusion is normal and students need to persevere. A class-developed poster, such as the one in Figure 3, can be helpful for this.

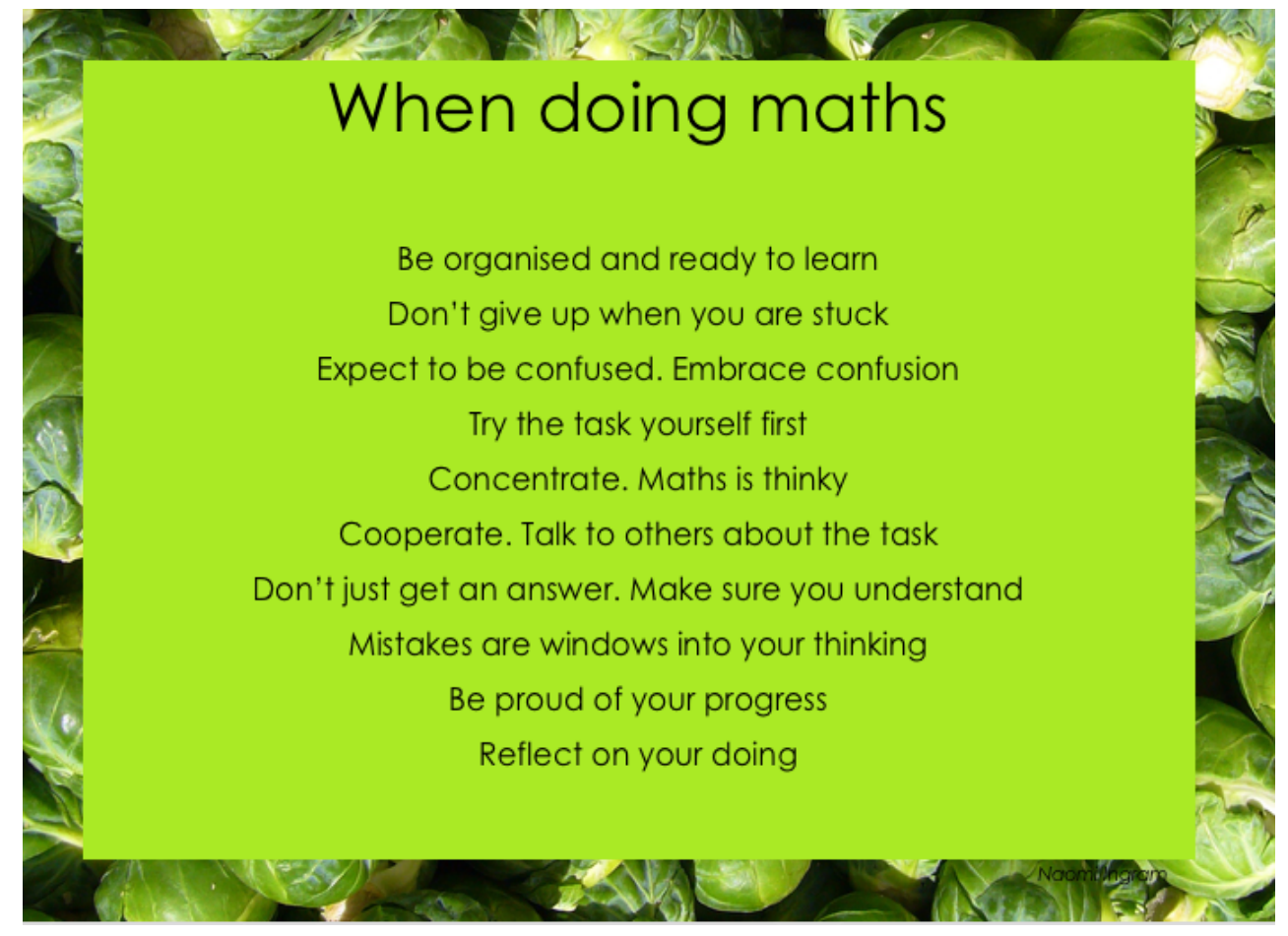

Figure 3. Reflecting on doing maths poster (Adapted from Ingram, Williamson-Leadley, Bedford \& Parker, 2015, p. 20)

This lesson structure is a useful way to scaffold teachers to enact effective pedagogies such as those suggested by Anthony and Walshaw (2009) but is reliant on the teachers' confidence in their teaching, and specifically, their mathematical content knowledge and pedagogical content knowledge. Teachers need understanding of potential connections 
between the problems they are posing and the mathematical content they want the students to learn. Teachers need to choose appropriate tasks, plan for the questions, prompts, and materials they will supply to the students. Teachers need to make decisions about when to move to the next phase, when to stop and reinforce the content, who to ask to feed back to the class, and when and how to summarise the lesson to emphasise the learning intentions. Hence, this lesson structure is strongly reliant on the craft of effective teaching.

\section{Conclusion}

Mathematics education in New Zealand has had many changes over time, with poor mathematics results often acting as the catalyst for new initiatives (e.g., the development of the Numeracy Development Project, as discussed by Holton, 2010). Recent international and national results have again acted as a catalyst for change. A variety of different approaches to mathematics education have been reported to be somewhat regional and inconsistent (Radio New Zealand, 9 December 2020).

It seems that a centralised, consistent and united management of change is needed for New Zealand mathematics education. There are many aspects that are well worth continuing with because they reflect our diverse and inclusive society, including teachers having an ethic of care in their classrooms. However, further resourcing is needed to build teachers' confidence so they are more likely to balance the ethic of care that exists in their classrooms with ensuring their students are practising challenging mathematics, where struggle and confusion is a normalised and accepted part of mathematics. The lesson structure, described above, is one suggestion for teachers of how this balance might be achieved.

Teachers, and especially those who have lower levels of confidence in their mathematics teaching practice, need support to grow their pedagogical content knowledge and mathematical content knowledge through targeted professional learning. Additionally, all teachers can practise mathematics themselves through enrolling in further study beyond the curriculum level they teach, by seeking challenging mathematical problems to solve, or simply by noticing and fully engaging in the mathematics that is embedded in their everyday lives.

\section{References}

Anthony, G., \& Walshaw, M. (2009). Effective pedagogy in mathematics (Vol. 19). International Academy of Education.

Hannula, M. (2014). Affect in mathematics education. In S. Lerman (Ed.), Encyclopedia of mathematics education (pp. 23-27). Springer.

Holton, D. (2010). Findings from the New Zealand Numeracy Development Project 2009. Ministry of Education.

Holton, D., Neyland A., Neyland J., \& Thomas B. (1999). Teaching problem solving: An introduction for primary and junior secondary teachers. Kingsham Press. 
Ingram, N., Asil, M., \& Berg, D. (2017). The impact of mathematics teaching efficacy on teachers' pedagogical practices. Proceedings of the European Association for Research on Learning and Instruction (EARLI) Conference, Finland, August 2017. https://earli.org/earli-2017

Ingram, N., Holmes, M., Linsell, C., Livy, S., McCormick, M., \& Sullivan, P. (2019). Exploring an innovative approach to teaching mathematics through the use of challenging tasks: A New Zealand perspective. Mathematics Education Research Journal, $1-26$.

Ingram, N., Williamson-Leadley, S., Bedford, H., \& Parker, K. (2015). Using show and tell tablet technology in mathematics. In R. Averill (Ed.), Mathematics and statistics in the middle years: Evidence and practice (pp. 18-34). NZCER.

Ministry of Education. (2007). The New Zealand Curriculum. Learning Media.

Mullis, I. V. S., Martin, M. O., Foy, P., Kelly, D. L., \& Fishbein, B. (2020). TIMSS 2019 International Results in Mathematics and Science. Retrieved from Boston College, TIMSS \& PIRLS International Study Center website. https://timssandpirls.bc.edu/timss2019/international-results/

National Monitoring Study of Student Achievement. (2019). Mathematics and statistics 2018: Key findings (No. 19). Educational Assessment Research Unit \& New Zealand Council for Educational Research, University of Otago. https://www.educationcounts.govt.nz/publications/series/nmssa/all-nmssa-publications

Noddings, N. (1995). Philosophy of education. Westview Press.

Sullivan, P., Askew, M., Cheesman, J., Clarke, D., Mornane, A., Roche, A., \& Walker, N. (2015). Supporting teachers in structuring mathematics lessons involving challenging tasks. Journal of Mathematics Teacher Education, 18, 123-140.

Naomi Ingram is a senior lecturer at the University of Otago, where she teaches and conducts research in mathematics education. In 2018, she was the recipient of the Teacher Education Forum of Aotearoa New Zealand's Emerging Teacher Educator award. She is a registered teacher and has continuing contact with the teaching community through research, educating pre-service teachers and professional development. She is in direct contact with mathematics associations throughout New Zealand in her work as a Bevan Werry speaker for the New Zealand Mathematics Association.

Email: naomi.ingram@otago.ac.nz

ORCiD: https://orcid.org/0000-0002-8131-054X 